\title{
Extracellular vesicle isolation and characterization: toward clinical application
}

\author{
Rong Xu, ${ }^{1}$ David W. Greening, ${ }^{1}$ Hong-Jian Zhu, ${ }^{2}$ Nobuhiro Takahashi, ${ }^{3,4}$ and Richard J. Simpson ${ }^{1,4}$ \\ 'Department of Biochemistry and Genetics, La Trobe Institute for Molecular Science, La Trobe University, Melbourne, Victoria, Australia. 'Department of Surgery, The University of Melbourne, Melbourne, \\ Victoria, Australia. ${ }^{3}$ Department of Applied Biological Science, Graduate School of Agriculture, and ${ }^{4} \mathrm{C}$ lobal Innovation Research Organization, Tokyo University of Agriculture and Technology, Tokyo, Japan.
}

\begin{abstract}
Two broad categories of extracellular vesicles (EVs), exosomes and shed microvesicles (sMVs), which differ in size distribution as well as protein and RNA profiles, have been described. EVs are known to play key roles in cell-cell communication, acting proximally as well as systemically. This Review discusses the nature of EV subtypes, strategies for isolating EVs from both cell-culture media and body fluids, and procedures for quantifying EVs. We also discuss proteins selectively enriched in exosomes and sMVs that have the potential for use as markers to discriminate between EV subtypes, as well as various applications of EVs in clinical diagnosis.
\end{abstract}

\section{Introduction}

Scientific and clinical interest in extracellular vesicles (EVs) has increased rapidly as evidence mounts that they may constitute a new signaling paradigm (1). EVs are secreted by most cells and carry diverse cargoes including proteins, RNA species (including mRNA, miRNA, lncRNA, and other RNA species), DNAs (mtDNA, ssDNA, dsDNA), and lipids that can be transported and exchanged between cells as a means of intercellular communication at both paracrine and systemic levels (2-7). It is clear that EVs carry preassembled complex biological information that elicits pleiotropic responses in recipient cells. Such responses underpin EV participation in the maintenance of normal and pathophysiological conditions $(4,8)$, including cancer $(9,10)$, neurodegenerative diseases $(11)$, rheumatic diseases (12), and infectious diseases (13-19). For a comprehensive review of our current understanding of the role of EVs in normal physiology, including reproduction, embryonic development, tissue repair, bone calcification, and the nervous system, see Yáñez-Mó and colleagues (20).

Due to their bioactive cargoes, EVs have innate therapeutic potential in diverse areas, such as cell-free cancer immunotherapy $(21,22)$ and regenerative medicine $(23,24)$. In light of their intercellular communication capability, it is not surprising that naturally derived EVs are also being exploited for the delivery of exogenous therapeutic reagents, such as small molecule antiinflammatory drugs (e.g., curcumin to activated monocytes; ref. 25), macromolecular drugs such as siRNA $(26,27)$, and vaccine-like tumor-associated antigens for presentation in the immune system $(28,29)$. For a review of $\mathrm{EV}$ application to cancer vaccines see Tan et al. (30). EVs also provide an as yet largely untapped source of diagnostic, prognostic, and predictive biomarkers (10, 12, 31). For a summary of recent clinical and preclinical investigations of EVbased therapies, see refs. 32 and 33 .

Conflict of interest: The authors have declared that no conflict of interest exists. Reference information: / Clin Invest. 2016;126(4):1152-1162. doi:10.1172/JCI81129.
Here, we will discuss several fundamental issues in the field of EV research, including how many EV subtypes occur naturally, whether they differ depending on cellular origin and physiological state, and how they differ with respect to biochemical properties and functional activity. Strategies for purifying EVs will be presented, with an emphasis on proteomic profiling as a means of categorizing EV subtypes.

\section{How many EV subtypes are there?}

It is well recognized that cells release essentially two EV subtypes that can be readily separated by differential centrifugation (DC): the larger size class (referred to as "microvesicles" or "shed microvesicles" [sMVs]) are heterogeneous (50 to $\sim 1,500 \mathrm{~nm}$ ) and sediment at approximately 10 to $14,000 \mathrm{~g}$, while the smaller size class (referred to as "exosomes") are relatively homogeneous in size $(50-120 \mathrm{~nm}$ ) and sediment at approximately 100,000 $\mathrm{g}$ (refs. 34-37 and Figure 1). Other vesicle types, such as apoptotic bodies (50-2000 nm) that are released by cells undergoing apoptosis (38), blood-derived vesicles (130-500 $\mathrm{nm}$ ) that are released upon platelet activation ("platelet dust") (39-41), and autophagosomes, (42) will not be covered in this review.

Vesicle annotation is an ongoing problem that has plagued the field over the past decade with varying names describing the two EV subtypes - this polemic has led to international efforts to standardize nomenclature and the quest for specific protein markers to distinguish one EV subtype from another (ref. 43 and Journal of Extracellular Vesicles [http://www.journalofextracellularvesicles. net/]). For position papers on standardization procedures for EV purification and minimal requirements for $\mathrm{EV}$ definition and function, see Witwer et al. (44) and Lotvall et al. (45), respectively.

It has been proposed that sMVs and exosomes arise from different biogenesis mechanisms, with sMVs directly budding from plasma membranes, while exosomes have endocytic origins and are formed as intraluminal vesicles (ILVs) by inward budding of the limiting membrane of late endosomes or multivesicular bodies (MVBs). MVBs subsequently fuse with the plasma membrane and release their sequested ILV contents 


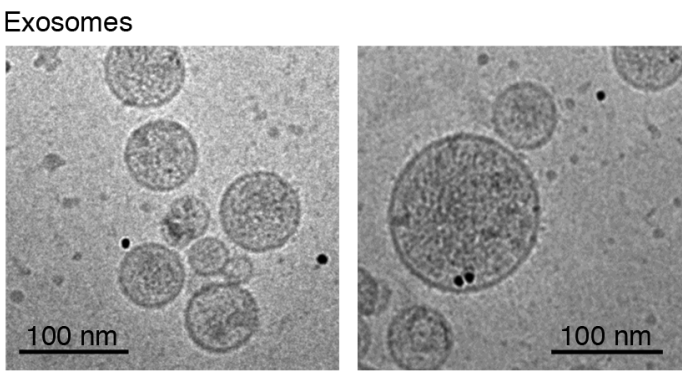

$50-120 \mathrm{~nm}$

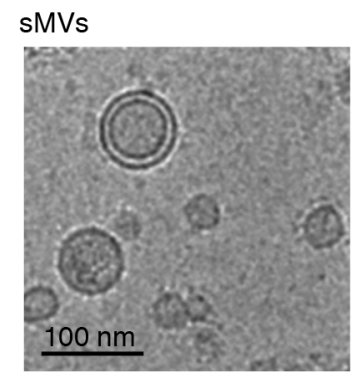

$50-120 \mathrm{~nm}$

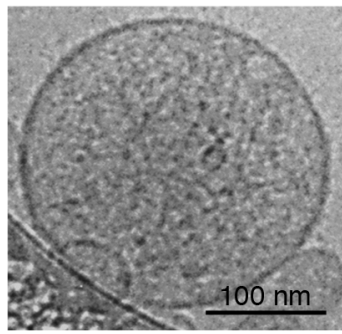

200-300 nm

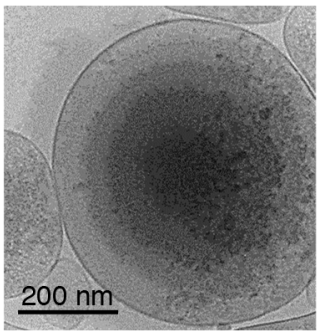

$>500 \mathrm{~nm}$

Figure 1. Characterization of distinct EV subtypes by cryoelectron microscopy. Electron micrographs of EV subtypes released into human colon cancer cell line LIM1863 cell-culture media. EVs were harvested from cell-culture media by sequential centrifugal ultracentrifugation, as described (37). EVs range in diameter from small $(50-120 \mathrm{~nm})$ (exosomes and sMVs) to intermediate $(\sim 200-300 \mathrm{~nm})$ (sMVs) and large $(>500 \mathrm{~nm})$ vesicles (sMVs).

as exosomes into the extracellular environment (Figure 2). Accruing literature reveals that the ubiquitous release of EVs by tumor cells and plasma tumor-associated EV levels in disease patients increase with cell invasiveness or disease progression (e.g., ovarian carcinoma, ref. 46; uveal melanoma, ref. 47; breast cancer, refs. 48, 49). For some time it has been known that the endosomal sorting complexes required for transport (ESCRTs), first discovered and named for their role in sorting membrane proteins from endosomes to lysosomes (50), make up the major machinery for MVB/ILV (and exosome) biogenesis (51). In addition to ESCRT-driven MVB/ILV formation (52, 53), it now appears that ESCRT-independent MVB/ILV formation may also occur. These ESCRT-independent mechanisms involve lipid-metabolizing enzymes such as neutral sphingomyelinase (nSMase), which hydrolyzes sphingomyelin to ceramide (54), and phospholipase D2 (PLD2), which hydrolyzes phosphatidylcholine into phosphatidic acid (55). ADP-ribosylation factor 6 (ARF6) and its effector, PLD2, are reported to regulate syntenin/Alix-driven exosome biogenesis, while ARF6-dependent activation of PLD2 also enables plasma membrane blebbing and release of sMVs $(34,55)$. While formation of MVBs and their intrinsic ILVs appears to involve multiple ESCRT-dependent and-independent molecular machineries, it is not clear whether these mechanisms are cell type dependent and whether they act simultaneously on the same or different MVBs within a given cell type (for excellent reviews of EV biogenesis mechanisms, see refs. 5, 51, 52). Evidence accumulated over the past 5 years suggests that ESCRTs not only play a central role in exosome biogenesis, but also regulate biogenesis of sMVs (51). However, mechanistic differences between ESCRT-dependent biogenesis of exosomes and sMVs are yet to be clearly defined. In the case of sMV biogenesis, the RhoA/Rho-associated kinase-dependent (ROCK-dependent) signaling pathway appears to be specifically involved in sMV formation in cancer cells. Interestingly, Cerione and colleagues show that attenuation of exosome release in highly aggressive MDAMB231 breast cancer cells by ectopic expression of dominant-negative mutant of the CHMP3 protein (the mammalian homolog of yeast VPS24 protein, which is essential for exosome secretion) does not impair the amount of sMV release (56). Likewise, processes that control sorting of specific molecules (protein and RNA species) into different EV subtypes, target cell recognition, and EV uptake are not well understood. While many molecules have been implicated in selective packaging into EVs of different proteins (e.g., ARF6, refs. 57, 58; arrestin domain-containing protein 1 [ARRDC1]) (59), posttranslational modifications $(60,61)$, and RNA species (62-64), the sorting mechanisms await further definition (for reviews, see ref. 65). A key issue hindering progress in understanding these key areas of EV biology has been the technical challenge of isolating homogeneous EV subpopulations suitable for molecular analysis.

While it is generally acknowledged that there are two broad categories of EVs, emerging evidence suggests that the exosome class contains subpopulations. For example, we found two distinct populations of exosomes released from the human colon carcinoma cell line LIM1863 grown in culture (66), one positive for the exosome surface marker A33 glycoprotein, the other positive for epithelial cell adhesion molecule (EpCAM). These exosome subpopulations were isolated from cell culture using sequential immunocapture with anti-A33 and anti-EpCAM mAbs coupled to magnetic beads. The two populations are identical in size and morphological properties based on electron microscopic analysis, and both contain stereotypical exosome marker proteins TSG101, Alix/PDCD6IP, and HSP70. However, gel electrophoresis followed by liquid chromatography-tandem mass spectroscopy (GeLC-MS/MS) analysis revealed that each exosome population has a distinct protein profile consistent with release from either apical (EpCAM-Exos) or basolateral (A33-Exos) surfaces of these highly polarized cells (66). Further, both exosome protein profiles were clearly distinguishable from those of sMVs isolated from the same cell culture. In a follow-up study using the same exosome and sMV preparations, we showed that these EV subtypes also have distinct miRNA-enrichment signatures, suggesting that these miRNA cargoes are biologically significant (67). These findings raise questions as to the nature of the underlying mechanisms responsible for selective packaging of exosome cargo. In another study, Ogawa and colleagues report two types of exosomes in human whole saliva that vary in size (20-80 nm and 30-250 nm) and morphology and contain stereotypical markers (TSG101, Alix, HSP70), but have different protein compositions (68). It is interesting that in both examples, two distinct exosomal populations were isolated in highly polarized cells (colon tumor line or oral mucosa). While tantalizing, the biological significance of these findings awaits further investigation. 

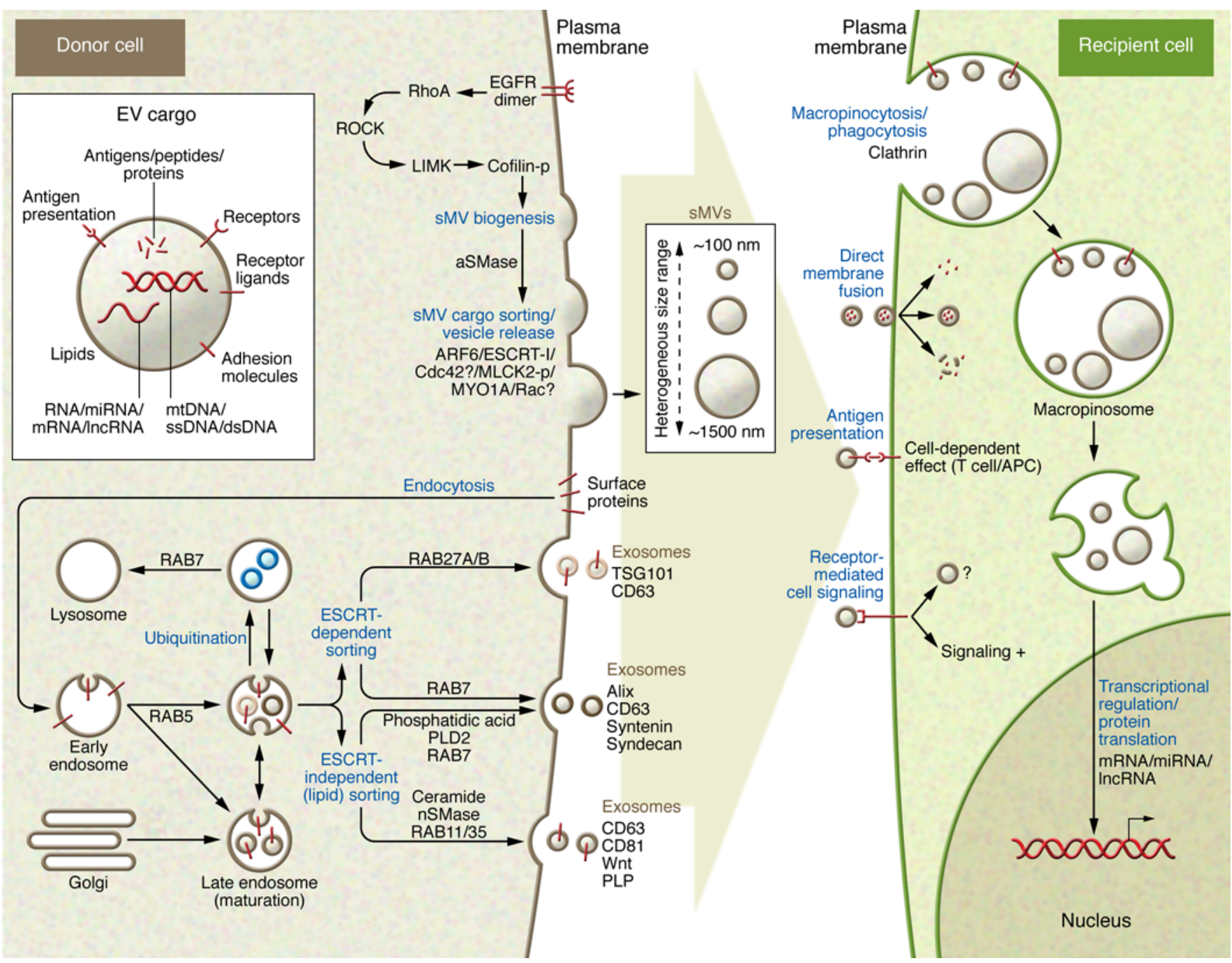

Figure 2. Proposed molecular machineries involved in EV (exosome/sMVs) secretion and recipient cell uptake. Components of donor cells are incorporated into EVs (exosomes, sMVs) that contain diverse cargoes, such as signaling proteins, transcriptional regulators, various RNA species, DNA, and lipids. Multiple machineries are thought to be involved in exosome biogenesis of ILVs and MVBs. ESCRT components are involved in an ESCRT-dependent intracellular pathway that traffics MVBs and their ILV contents (exosomes) out of the cell, while other ESCRT-independent pathways (lipid dependent) have also been described. Members of the Rab GTPase family have been shown to modulate exosome secretion and are thought to act on different MVBs along ESCRT-dependent and -independent endocytic pathways. It is not known whether each of these pathways acts on different MVBs or on the same MVB concomitantly or how exosome/ILV-loaded MVBs differ from those destined for lysosomes. Even less is known about the molecular machinery regulating outward budding of the plasma membrane and sMV release, apart from a requirement of ARF6, acid sphingomyelinase activity, and some ESCRT components (ESCRT-I). EVs may interact with recipient cells by direct signaling through ligand/receptor molecules on their respective surfaces or by their uptake via direct fusion of EV and recipient cell plasma membrane $(110,111)$ through lipid raft-, clathrin-, and calveolae-dependent endocytosis, macropinocytosis, and phagocytosis (112-117). EVs can be involved in antigen presentation and in the transfer of both MHC molecules and antigens, thereby participating in immune regulation (118-120). APC, antigen-presenting cell.

\section{Importance of working with highly purified EV populations}

As discussed above, EVs are very likely to be carriers of information between cells as well as having great promise as specific pharmaceutical targeting vehicles and as sources of diagnostic and prognostic markers. However, studies to elucidate these roles can be confounded by the presence of EV subtypes with different mechanisms of biogenesis, organelle origin, and constituent makeup. It is therefore clear that functionality and diagnostic/therapeutic uses can only be truly defined once the range of $\mathrm{EV}$ subpopulations from a given source are fully described and isolated for complete analy- sis of constituent molecules. If functional differences between EV subtypes do indeed exist, it is unclear how this might affect possible side effects if impure samples are used in a clinical setting. For biodistribution and biokinetic studies, highly purified vesicle populations are an absolute necessity. Thus, for the field to progress and live up to expectations, there is an imperative to overcome the technical challenges associated with purifying EVs to homogeneity as well as develop procedures for their accurate quantification.

There is a large body of literature describing protocols for purifying EVs (2, 37, 69-71), assessing their purity (72), and identifying shortcomings (71); for a comparison of yields of protein 


\section{Table 1. Commonly used methods of isolating EVs}

\begin{tabular}{|c|c|c|c|c|}
\hline Method & Detail/references & EV yield & Purity & Scability \\
\hline$D C$ & $\begin{array}{l}\text { Used to isolate crude EV/exosome mixtures from conditioned media (CM) by DC at } \\
\sim 100,000 \mathrm{~g} \text { after cell debris/intact cells are removed by low- } g \text { force centrifugation } \\
\text { steps }(\sim 50 \mathrm{~g} / 2,000 \mathrm{~g}) \text {. After an initial low- } \mathrm{g} \text { force } \mathrm{spin}(10-14,000 \mathrm{~g}) \text { after cell debris } \\
\text { removal, crude sMVs can be isolated from the CM }(34,36,66) \text {; purified exosomes can } \\
\text { be subsequently harvested from the resultant } \mathrm{sMV} \text {-depleted CM by centrifugation at } \\
100,000 \mathrm{~g} \text {. This approach does not separate EVs from possible high } \mathrm{M}_{\mathrm{r}} \text { protein oligomers/ } \\
\text { protein-RNA complexes and viruses }(35,44) \text {. }\end{array}$ & $\begin{array}{l}\text { Medium } \\
\text { (high molecular mass protein } \\
\text { complexes, issues with nonselectivity } \\
\text { and sample heterogeneity) }\end{array}$ & Low & $\begin{array}{c}\text { Medium } \\
(\mu \mathrm{l}-\mathrm{I})\end{array}$ \\
\hline $\begin{array}{l}\text { Sucrose cushion } \\
\text { centrifugation }\end{array}$ & $\begin{array}{l}\text { This method is a variation on sucrose DGC (69), typically used for morphological analysis } \\
\text { of EVs (e.g., electron microscopy) because it minimizes mechanical stress encountered in } \\
D C \text { methods. }\end{array}$ & $\begin{array}{l}\text { Medium } \\
\text { (sample loss during fractionation, } \\
\text { exosomes, and viral particles of } \\
\text { similar densities copurify) }\end{array}$ & High & $\begin{array}{c}\text { Medium } \\
(\mu \mathrm{l}-\mathrm{ml})\end{array}$ \\
\hline
\end{tabular}
principles can be applied to simple, readily made chromatography columns operated under gravity or by inexpensive pumps. Widely used for isolating EVs from plasma samples (90) and has been adapted for high-throughput clinical samples (95). This method overcomes many of the problems associated with EV isolation from plasma/ serum using $D C / D C C$ - e.g., coisolation of EVs with large $M_{r}$ protein aggregates and lipoproteins $(90,94,95)$.

\begin{abstract}
$A C$
$\mathrm{AC}$ methods for isolating EVs rely on an affinity tag ( $\mathrm{mAb}$ that targets an EV surface antigen, biospecific peptide [ref. 122], or proteoglycan affinity reagents [refs. 76, 77, 123]) covalently fused to either magnetic or agarose beads. mAbs that have been successfully employed as bait are described in refs. $35,70,102$, and 124-132. AC was reported to be more effective than DG and DGC for isolating EVs from LIM1863 cells (35).
\end{abstract}

Microfluidic devices

Synthetic polymer-based
precipitation
Three categories of microfluidic devices: (a) trapping exosomes with an immune-affinity

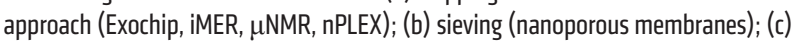
trapping exosomes on porous structures (nanowire on micropillars) $(133,134)$.

$\begin{array}{ccc}\text { Low } & \text { High } & \text { Low } \\ \text { (Ab selection/availability dependent) }\end{array}$

$(\mu \mathrm{l}-\mathrm{ml})$

Membrane filtration

Several synthetic water-soluble polymers, commonly used as protein/virus/particle precipitants, are now used to rapidly isolate crude $\mathrm{EV}$ mixtures from CM and biofluids (135-137). These methods afford a rapid EV isolation/concentration step for the purpose of diagnostic assay of known EV-associated biomarkers.
Typical commercial devices for this method include stirred ultrafiltration cells (operated

\section{Medium}

Low Low

$(\mu l)$

\section{under $\mathrm{N}_{2}$ pressure and containing a magnetic stir bar for mixing) and ultrafiltration spin
columns/tubes operated using low centrifugal force. Nanomembrane ultrafiltration spin \\ under $\mathrm{N}_{2}$ pressure and containing a magnetic stir bar for mixing) and ultrafiltration spin
columns/tubes operated using low centrifugal force. Nanomembrane ultrafiltration spin devices, equipped with low protein-binding membranes, have recently been applied in clinical laboratories for the isolation of EVs from multiple, low-volume, urinary (138, 139), and blood plasma samples (140). This approach has been modified to enable the fractionation of highly purified sMVs and exosomes from the same CM of colon carcinoma LIM1863 cells (37).}

and RNA species using different isolation procedures see Alvarez et al. $(44,73)$. Isolation strategies typically used, along with approximate yields and scalability, listed in Table 1, include DC, density-gradient centrifugation (DGC), sucrose cushion centrifugation, gel-permeation chromatography (GPC), affinity capture (AC), microfluidic devices, synthetic polymer-based precipitation, and membrane filtration. It is obvious from this long list that there are varying methodologies for purifying (enriching) EVs, but, as yet, no gold standard method that would allow researchers to conduct interlaboratory comparisons. In an effort to evaluate commonly used methods for isolating exosomes, Tauro and colleagues compared DC, DGC, and AC procedures using colorectal cancer cell line LIM1863 culture supernatant as source material $(35,70)$. Using a mass spectrometry approach to profile protein compositions and label-free spectral counting $(4,66,74)$ to evaluate the effectiveness of each method, AC using magnetic 
Table 2. Methods for quantifying EVs

\begin{tabular}{|c|c|c|c|c|c|c|}
\hline Method & Equipment & Analysis and range & EVs analyzed & Major advantages & Major limitations & References \\
\hline $\begin{array}{l}\text { Nanoparticle tracking } \\
\text { analysis (NTA) }\end{array}$ & $\begin{array}{l}\text { LM20, LM10, LM14, } \\
\text { NS500 }\end{array}$ & $\begin{array}{l}\text { Size distribution }(10 \mathrm{~nm}-2 \mu \mathrm{m}) \\
\text { concentration } \\
\left(10^{7} \sim 10^{9} \text { particles } \mathrm{ml}^{-1}\right)\end{array}$ & Exos, sMVs & $\begin{array}{l}\text { Accurate for both monodisperse } \\
\text { and polydisperse; } \\
\text { calibration particle standards }\end{array}$ & $\begin{array}{c}\text { Size }>70 \mathrm{~nm} \\
\text { (fluorescent-NTA, }>50 \mathrm{~nm} \text { ) }\end{array}$ & $41,141-146$ \\
\hline $\begin{array}{l}\text { Dynamic light } \\
\text { scattering (DLS) }\end{array}$ & Nano ZS & $\begin{array}{l}\text { Size distribution } \\
(0.3 \mathrm{~nm}-1 \mu \mathrm{m})\end{array}$ & Exos, sMVs & $\begin{array}{l}\text { Accurate for monodisperse samples; } \\
\text { lower size }(<30 \mathrm{~nm})\end{array}$ & $\begin{array}{l}\text { Large particles can compromise the } \\
\text { results, inaccurate for polydisperse } \\
\text { samples }\end{array}$ & 141,146 \\
\hline $\begin{array}{l}\text { Resistive pulse sensing } \\
\text { (RPS) }\end{array}$ & qNano & $\begin{array}{c}\text { Size distribution } \\
\text { (30 nm-1 } \mu \mathrm{m}) \text {, concentration } \\
\left(10^{7} \sim 10^{10} \text { particles } \mathrm{ml}^{-1}\right)\end{array}$ & Exos & Surface charge & $\begin{array}{l}\text { For unknown size distribution, } \\
\text { insufficient for detection of all } \\
\text { particles, size }>70 \mathrm{~nm}\end{array}$ & 142,143 \\
\hline $\begin{array}{l}\text { Flow cytometry } \\
\text { (FACS) }\end{array}$ & BD flow cytometer & $\begin{array}{c}\text { Distribution Size } \\
\text { (200 nm }-1 \mu \mathrm{m}) \text { concentration } \\
\left(10^{6} \sim 10^{9} \text { particles } \mathrm{ml}^{-1}\right)\end{array}$ & Exos, sMVs & $\begin{array}{l}\text { Low particle concentration } \\
\left(10^{6} \text { particles } \mathrm{ml}^{-1}\right)\end{array}$ & $\begin{array}{l}\text { Size > } 200 \text { nm. For exos, not } \\
\text { absolute size measurement }\end{array}$ & $\begin{array}{c}80,85,143 \\
144,147\end{array}$ \\
\hline $\begin{array}{l}\text { Electron microscopy } \\
\text { (EM) }\end{array}$ & $\begin{array}{c}\text { TEM: JEOL JEM-2010 } \\
\text { Cryo-EM: Tecnai G2 F30, } \\
\text { Tecnai F20, } \\
\text { Titan Krios }\end{array}$ & $0.1 \mathrm{~nm}-\mu \mathrm{m}$ range & Exos, sMVs & $\begin{array}{l}\text { TEM/cryo-EM: direct visualization } \\
\text { and observation of EVs, } \\
\text { EV structure/morphology; } \\
\text { cryo-EM: preserves membranes } \\
\text { in native state }\end{array}$ & $\begin{array}{l}\text { TEM: fixation induces shrinking of } \\
\text { EV structure, equipment, cost }\end{array}$ & $4,5,43,107$ \\
\hline
\end{tabular}

cryo-EM, cryoelectron microscopy; TEM, transmission electron microscopy; exos, exosomes.

beads coated with a mAb directed to the exosomal surface was clearly superior to DC and DGC for isolating exosomes. Additionally, as demonstrated for mAb purification, AC methodology is more scalable than precipitation/centrifugation-based methods (75). Clearly, a major drawback of AC is the availability of a suitable $\mathrm{mAb}$ directed toward a specific vesicle surface protein as "bait." Interestingly, Balaj and colleagues describe an elegant AC method for purifying EVs from cell-culture media and human plasma using heparin-AC based on their earlier observation that heparin blocks EV uptake in cells $(76,77)$. Given that heparin/heparin sulfate can interact with intact cell surfaces (78), it is unclear whether heparin-AC methodology can discriminate between exosomes and sMVs. In any event, this method promises to be a onemethod-fits-all approach for isolating EVs from cell-culture media and blood, especially if used as a final polishing method when combined with other EV-fractionation approaches (e.g., ref. 37).

Using sequential centrifugal ultrafiltration (SCUF), we recently developed an unbiased EV-fractionation method to address the question of how many EV subtypes might be released from cells into culture media (37). This SCUF method employed hydrophilic PVDF membranes of various pore sizes over the range 0.1 to 0.65 $\mu \mathrm{m}$ and low $g$ centrifugal force. Fractionated EVs were examined morphologically using cryoelectron microscopy, and vesicle particle size was measured by dynamic light scattering; comparative protein profiling was undertaken by GeLC-MS/MS. Our findings revealed that only two EV subtypes are released from LIM1863 colon cancer cells (these make up more than $98 \%$ of total vesicles in sample): one characteristic of exosomes ( $\mathrm{Alix}^{+} / \mathrm{TSG} 101^{+} /$ $\mathrm{CD} 3^{+} / \mathrm{CD} 81^{+}$and relatively homogeneous in size [range $30-100$ $\mathrm{nm}]$ ), and the other characteristic of sMVs (heterogeneous in size ranging over 30 to $1300 \mathrm{~nm}$ diameter). Strikingly, sMVs were negative for Alix/TSG101/CD63 and CD81. The buoyant densities of exosomes and sMVs, determined by OptiPrep DGC, were 1.10 to $1.11 \mathrm{~g} / \mathrm{ml}$ and 1.18 to $1.19 \mathrm{~g} / \mathrm{ml}$, respectively. A major finding from this was that 350 proteins were uniquely identified in sMVs, when compared with exosomes, many of which have the potential to provide markers for this EV subtype (e.g., members of the septin family, kinesin-like protein [KIF23], exportin-2/chromosome segregation like-1 protein [CSE1L/CAS], and Rac GTPase-activating protein 1 [RACGAP1]). While these marker proteins have been observed in many different colon cancer cell line-derived sMV preparations (Supplemental Table 1; supplemental material available online with this article; doi:10.1172/JCI81129DS1), their universality for this EV subtype must await further studies using an extensive range of cell types and body fluids. Interestingly, while both exosomes and sMVs induced invasion of recipient fibroblast cells in the Transwell-Matrigel invasion assay, sMVs exhibited approximately 3-fold greater invasive activity than exosomes (37). In another study, Menck and colleagues report that breast tumor-derived microvesicles ( $\mathrm{sMVs}$ ) induce human breast cancer invasion (MCF-7 and SK-BR-3 cells) to a significantly greater extent than exosomes (79). While further studies are necessary, there is an emerging appreciation that sMVs and exosomes might be functionally distinct.

\section{How to measure EV purity?}

One of the most vexing problems in EV biology is how to accurately measure and assess EV purity (72). This becomes a critical issue when evaluating $\mathrm{EV}$ dosage for functional studies, recipient cell activation, and achieving therapeutic efficacy. How does one measure EV purity? In biochemical terms, this is akin to measuring EV "specific activity," i.e., by expressing the concentration of a specific EV surface-marker antigen (e.g., by ELISA assay or Western blot/FACS/EV array) or EV protein concentration as a ratio of vesicle concentration (i.e., "protein-to-particle" ratio; ref. 72). There are numerous methods for measuring vesicle/particle numbers (80), including optical methods, such as nanoparticle tracking analyses, dynamic light scattering, and flow cytometry, and 
nonoptical methods, such as resistive pulse sensing, transmission electron microscopy, and Raman spectroscopy (81). For a summary of these methods, along with advantages and limitations, see Table 2. While at present there is no single method allowing accurate phenotyping, sizing, and enumeration for the whole range of $\mathrm{EV}$ types, a microarray platform has been recently described for multiparametric MS-based quantitation and fluorescence-based phenotyping (82). For accurate protein concentration measurements, commonly used methods include 1D-SDS-PAGE coupled to densitometry employing SYPRO Ruby staining $(35,70)$ and micro-BCA (72); while both methods are linear over a protein concentration range of $\mu \mathrm{g} / \mathrm{ml}$ to $\mathrm{mg} / \mathrm{ml}$, the SYPRO Ruby method is linear and sensitive at sub-ng levels per gel band. However, several caveats make the task of measuring EV number and protein content difficult. For example, current particle tracking approaches are typically biased toward a designated EV size range (i.e., do not evaluate the entire global field) and cannot discriminate EVs from nonvesicular material (e.g., membrane fragments). On the other hand, obtaining accurate protein concentrations of EVs is not without its problems either; for example, the potential problem of noncovalently bound proteins copurifying with EVs has yet to be adequately addressed. There is also the issue of discriminating between copurifying artifactual proteins (contaminants) and the possibility of physiologically important noncovalent EV surface proteins, or oligomeric protein complexes. It is anticipated that robust "membrane shaving" experiments, which involve gentle treatment EVs with proteases to digest (shave) surface proteins while maintaining integrity of EV luminal proteins, will reveal much about the luminal contents of EVs and also resolve issues such as (a) whether RNA species are selectively packaged as integral components of EVs (83) and not just bound to the outer surface of the vesicle complexed with RNA chaperone proteins (i.e., in the extracellular space), and (b) how to discriminate between integral EV proteins and copurifying artifact proteins (e.g., high-molecular weight oligomers and nonselective sticky/adhesive proteins).

Another question that affects EV dosage calculations is whether EV particle number/protein concentration remains static during cancer (disease) progression. While there is accumulating evidence that in late-stage cancers more EVs are released (46-49, $84,85)$ and EV cargo contents (e.g., proteins) increase $(74,84,86$, $87)$, the question of whether EV volumes and total cargo content increase during cancer progression remains unresolved.

\section{Isolation of EVs from body fluids}

While most early studies evaluating methods for isolation and purification of EVs were performed on material harvested from cellculture media (see Table 1 for a summary of commonly used isolation methods), there is tremendous scientific and clinical interest in body fluid-derived EVs (e.g., blood, urine, malignant ascites) due to their clinical information (refs. 8, 88, and Supplemental Table 2). However, the isolation of EVs from blood, for example, presents formidable challenges, such as limited availability of valuable biospecimens, the presence of high-abundance proteins and lipoprotein particles, the physical properties of this matrix (e.g., viscosity and density), and the presence of a multitude of EVs originating from many different cell types in blood (although the vast majority originating from erythrocytes and platelets [platelet dust; ref. 39]). Hence, the desired EV subtype originating from a specific disease may represent only a small percentage of the total EV population, with this percentage depending upon the nature of the standard operative procedure (SOP) employed for blood collection (i.e., extent of platelet vesiculation). Additionally, EVs may be coated with glycoproteins or glycolipids, which may cause aggregation and low yields if DC isolation methods are employed. Needless to say, if the EV field, as it applies to clinical diagnosis/disease prognosis, is to mature and reach its full potential, then standardization of critical parameters, such as blood collection, processing and storage, methods for isolating EVs from plasma, and EV sizing and enumeration, need to be addressed. For example, there are contrary reports in the literature as to the preferred plasma collection method (i.e., usage of anticoagulants citrate, EDTA, or heparin) (89-91). In this regard, in 2013, two international bodies - the International Society for Extracellular Vesicles (ISEV) and the International Society for Thrombosis and Haemostasis (ISTH) - in their guidelines and recommendations regarding standardization of sample collection and handling, discourage the use of heparin-based anticoagulants $(44,92)$. More recently a Microvesicle Analysis Interest Development Group was established under the auspices of the International Society for Advancement of Cytometry (ISAC) to discuss efforts for standardizing EV sample preparation and flow cytometry measurement approaches (93). There is a considerable body of research supporting the notion that size-exclusion chromatography (SEC) coupled with membrane filtration is the preferred procedure for isolating EVs from plasma/serum $(71,90,94,95)$; the preferred method for harvesting EVs after SEC, i.e., precipitation versus centrifugation, requires further evaluation (95). For urinary EV isolation procedures, see Alvarez and colleagues (73) for a comparison of different methods based on DC and commercial exosome precipitation protocols. Sáenz-Cuesta et al. further compared different EV isolation protocols with blood and urine samples and several types of analysis (flow cytometry, nanoparticle tracking analysis, and electron microscopy), taking into account facilities of a nonspecialized core laboratory (88). A detailed list of methods for isolating EVs from various body fluids is given in Supplemental Table 2 .

With the emerging interest in the use of EVs as clinical diagnostic reagents, several high-throughput diagnostic platforms have been developed, ranging from classical sandwich ELISA-based microarray chip technologies $(87,96)$ to the use of sophisticated platforms involving immunomagnetic exosome RNA (iMER) analysis (97), miniaturized micro-nuclear magnetic resonance $(\mu \mathrm{NMR})$ microfluidic chip system (98), Exochip (99), and label-free high-throughput nano-plasmonic exosome assay (nPLEX) using surface plasmon resonance (SPR) (100) (see Table 3 for a list of EV-based diagnostic approaches). When coupled to high-throughput procedures for harvesting EVs from peripheral blood (95), these platforms promise to extend EV research into routine diagnostic and therapeutic settings. While several clinical studies have employed multiplexed protein markers (e.g., 37 proteins; ref. 96) and a combination panel of proteins and miRNAs (4 and 4, respectively; ref. 101) for disease diagnosis, Melo and colleagues (86) report that a single protein molecule (glycipan-1 [GPC1]) anchored to circulating EVs can be employed to diagnose late-stage pancreatic 


\section{Table 3. Application of EVs in clinical diagnosis}

\begin{tabular}{|c|c|c|c|c|c|}
\hline Method & Analysis and detection & Biofluid & EV type & Current application(s) & Reference \\
\hline Exos sandwich ELISA assay & Sandwich ELISA, 1-3 Abs & Plasma & Exos & $\begin{array}{l}\text { Pancreatic ductal adenocarcinoma } \\
\qquad(n=40)\end{array}$ & 87 \\
\hline \multirow[t]{2}{*}{ FACS } & Exos-bound beads & $250 \mu \mathrm{l}$ serum & Exos & $\begin{array}{l}\text { Pancreatic ductal adenocarcinoma } \\
\qquad(n=190)\end{array}$ & 86 \\
\hline & Exos-bound beads & $1-1.5 \mathrm{ml}$ serum & Exos & $\begin{array}{l}\text { Pancreatic cancer } \\
\qquad(n=131)\end{array}$ & 101 \\
\hline EV array & $\begin{array}{l}\text { Sandwich ELISA-based method, Multiplex capability - } \\
\text { different Abs (37) probed to capture Exos }\end{array}$ & $10 \mu \mathrm{l}$ Plasma & Exos & $\begin{array}{l}\text { Advanced non-small cell } \\
\text { lung carcinoma } \\
(n=109)\end{array}$ & 96 \\
\hline ExoScreen & $\begin{array}{l}\text { Amplified luminescent proximity homogeneous assay } \\
\text { using photosensitizer beads }\end{array}$ & $5 \mu \mathrm{l}$ serum & Exos & $\begin{array}{l}\text { Colorectal cancer patients } \\
\qquad(n=194)\end{array}$ & 148 \\
\hline $\begin{array}{l}\text { Ready-made } \\
\text { chromatography columns }\end{array}$ & Sepharose CL-2B column (CellCS) & $\begin{array}{l}\text { Plasma } \\
\text { (up to } 1.5 \mathrm{ml} \text { ) }\end{array}$ & Exos & Healthy donor plasma & 95 \\
\hline Exochip & Immunoaffinity-based microfluidic device for on-chip & $\begin{array}{l}\text { Serum } \\
(400 \mu l)\end{array}$ & Exos & $\begin{array}{l}\text { Pancreatic cancer patients } \\
\qquad(n=5)\end{array}$ & 99 \\
\hline iMER & Immunomagnetic Exos RNA analysis & Serum & Exos & $\begin{array}{l}\text { Glioblastoma multiforme patients } \\
\qquad(n=17)\end{array}$ & 97 \\
\hline$\mu \mathrm{NMR}$ & Miniaturized micronuclear magnetic resonance & Plasma & Exos & $\begin{array}{l}\text { Glioblastoma multiforme patients } \\
\qquad(n=30)\end{array}$ & 149 \\
\hline nPLEX & Transmission SPR through periodic nanohole & Ascites & Exos & $\begin{array}{l}\text { Ovarian cancer patients } \\
\qquad(n=20)\end{array}$ & 100 \\
\hline
\end{tabular}

cancer using only a single drop of blood for analysis. At this stage, there is no international consensus as to which EV isolation procedure or diagnostic platform is likely to be translatable into the clinic $(32,33)$.

\section{Distinguishing EVs based on protein expression: current status}

As discussed above, two broad categories of EVs are released from the human colon cancer cell line LIM1863 (37), exosomes and sMVs. Over the past decade, our laboratory has accumulated exhaustive proteomic profiling data sets for highly purified $\mathrm{EV}$ subtypes (exosomes and sMVs) from the human colon cancer cell lines LIM1863 (35, 37, 66), HCT116, SW1222, LIM1215 (102), SW480, SW620 (74), human NIH3T3 fibroblast, and Rastransformed NIH3T3 fibroblast cells (103), and the Madin-Darby canine kidney (MDCK) cell line and an MDCK cell line transformed with oncogenic H-Ras (21D1 cells) (4). These extensive proteomic data sets (RAW files) are publically accessible through PeptideAtlas (104). Interrogation of these data sets (Supplemental Table 1) reveals that the stereotypic exosome protein markers TSG101, Alix/PDCD6IP, and CD63 are exclusively enriched in exosomes; they are not present in sMVs. Other proteins exclusively enriched in exosomes that warrant further examination as potential selective markers include Disco-interacting protein 2 homolog B (DIP2B), members of the 4-transmembrane protein family TSPAN6 and TSPAN3 (105), arrestin domain-containing protein 1 (ARRDC1), immunoglobulin superfamily member 8 (IGSF8), and CD82. Numerous proteins found exclusively in sMVs (e.g., KIF23, RACGAP1, chromosome segregation 1-like protein, exportin-2 [CSE1L/CAS]) warrant further study as to their potential use as discriminatory markers for sMVs. The high abundance of RNA binding proteins such as the family of heterogeneous nuclear ribonucleoproteins (hnRNPs) in both EV subtypes is consistent with their proposed role in selective loading of RNA cargoes (106). This study is a first attempt at defining protein markers that would allow discrimination between exosomes and sMVs; however, this study was restricted to human colon cancer cell lines and the dog kidney MDCK cell line. Needless to say, for general applicability, these studies need to be extended to other tissue-specific cell lines and biopsy samples.

\section{The future}

Currently, there is general consensus in the field that there are at least two types of EVs: exosomes ( 50-120 nm diameters) and sMVs ( $50-1500 \mathrm{~nm}$ in diameter). Due to the extensive size heterogeneity of sMVs, it is not yet clear whether this fraction makes up a single vesicle subtype with respect to composition and functional properties in a continuum of oligomeric states, perhaps in dynamic equilibrium. For example, are greater than $1-\mu \mathrm{m}$ diameter oncosomes and greater than $0.5-\mu \mathrm{m}$ sMVs functionally identical? Further research is required to fully define the complete functional range of EV fractions from a single source. To date, most EV research has been conducted using vesicles isolated from cell culture. Encouragingly, recent cryo-electron microscopy with receptor-specific gold staining of an $\mathrm{EV}$ fraction from healthy patient plasma reveals an overall particle size distribution similar to that observed in cell culture (107). Highresolution mass spectrometry (37) and deep sequencing (67) of highly purified exosome and sMV populations from colon tumor cells show distinct protein and miRNA profiles for the two EV 
subtypes. While these results have provided the opportunity to develop specific markers for discriminating EV subtypes in a colon cancer context, further studies using highly purified EVs from a broad spectrum of tissue types are required to confirm general applicability for these markers. In this regard, the exciting development of a heparin-AC method (77) promises to overcome limitations of many $\mathrm{EV}$ isolation strategies, especially those that lack a specific immuno-AC step, in our opinion the preferred method for isolating EVs (35). Whether the heparinbinding affinity of exosomes and sMVs differ sufficiently to allow discrimination of subtypes by this method remains to be determined. However, when coupled with other methods such as SCUF (37) or DC, heparin affinity-based isolation techniques should afford an excellent final polishing step.

In the clinical context, a fundamental issue is the technical challenge of EV quantification. While great strides have been made (see Table 2) in ability to accurately measure both EV particle numbers and protein content (72), there is still a pressing need to standardize EV enumeration procedures across laboratories. This is particularly important for allowing comparison of functional data and defining $\mathrm{EV}$ dosage for clinical trial purposes. At present, there is much debate as to whether EV dosage should be defined by number of vesicle particles, amount of vesicle protein, or expressing dosage as a vesicle number to protein ratio. This question must be addressed for clinical applications to be advanced. As outlined above, improvements in EV-subtype iso- lation strategies (Table 1) promise to yield highly purified EVs for biomarker discovery. As novel EV subtype markers continue to emerge, the opportunity to employ high-resolution fluorescence microscopy $(108,109)$ should improve our understanding of EV subtype biogenesis. Needless to say, a better understanding of $\mathrm{EV}$ biology together with standardized methods for EV quantification, isolation and storage, molecular characterization, and establishing potency assays will greatly enhance the future promise for EV-based diagnostic and therapeutic applications.

\section{Acknowledgments}

The authors were supported, in part, by the National Health and Medical Research Council (NHMRC) of Australia: project grants no. 1057741 (to R.J. Simpson and D.W. Greening) and no. 433619 (to H.J. Zhu) and a La Trobe University Leadership RFA grant (to D.W. Greening). This work was also supported by Operational Infrastructure Support Program funding provided by the Victorian Government. R. Xu is supported by a La Trobe University Post Graduate Fellowship. The authors acknowledge the input of Donna Dorow for proofreading this Review.

Address correspondence to: Richard J. Simpson, Department of Biochemistry and Genetics, La Trobe Institute of Molecular Sciences (LIMS), LIMS Building 1, Room 412, La Trobe University, Melbourne, Victoria 3086, Australia. Phone: 61.3.9479.3199; E-mail: Richard.simpson@latrobe.edu.au.
1. Antonyak MA, Cerione RA. Emerging picture of the distinct traits and functions of microvesicles and exosomes. Proc Natl Acad Sci U S A. 2015;112(12):3589-3590.

2. Simpson RJ, Lim JW, Moritz RL, Mathivanan S. Exosomes: proteomic insights and diagnostic potential. Expert Rev Proteomic. 2009;6(3):267-283.

3. Rak J, Guha A. Extracellular vesicles vehicles that spread cancer genes. Bioessays. 2012;34(6):489-497.

4. Tauro BJ, et al. Oncogenic H-ras reprograms Madin-Darby canine kidney (MDCK) cellderived exosomal proteins following epithelialmesenchymal transition. Mol Cell Proteomics. 2013;12(8):2148-2159.

5. Colombo M, Raposo G, Thery C. Biogenesis, secretion, and intercellular interactions of exosomes and other extracellular vesicles. Annu Rev Cell Dev Biol. 2014;30:255-289.

6. Christianson HC, Svensson KJ, Belting M Exosome microvesicle mediated phene transfer in mammalian cells. Semin Cancer Biol. 2014;28:31-38.

7. Rajendran L, et al. Emerging roles of extracellular vesicles in the nervous system. J Neurosci. 2014;34(46):15482-15489.

8. De Toro J, Herschlik L, Waldner C, Mongini C. Emerging roles of exosomes in normal and pathological conditions: new insights for diagnosis and therapeutic applications. Front Immunol. 2015;6:203.

9. Kucharzewska P, Belting M. Emerging roles of extracellular vesicles in the adaptive response of tumour cells to microenvironmental stress. JExtracell Vesicles. 2013;2.

10. Rak J. Extracellular vesicles - biomarkers and effectors of the cellular interactome in cancer. Front Pharmacol. 2013;4:21.

11. Grad LI, et al. Intercellular propagated misfolding of wild-type $\mathrm{Cu} / \mathrm{Zn}$ superoxide dismutase occurs via exosome-dependent and -independent mechanisms. Proc Natl Acad Sci U S A. 2014;111(9):3620-3625.

12. Beyer C, Pisetsky DS. The role of microparticles in the pathogenesis of rheumatic diseases. Nat Rev Rheumatol. 2010;6(1):21-29.

13. Hosseini HM, Fooladi AA, Nourani MR, Ghanezadeh F. The role of exosomes in infectious diseases. Inflamm Allergy Drug Targets. 2013;12(1):29-37.

14. Meckes DG Jr. Exosomal communication goes viral. J Virol. 2015;89(10):5200-5203.

15. Mantel PY, Marti M. The role of extracellular vesicles in Plasmodium and other protozoan parasites. Cell Microbiol. 2014;16(3):344-354.

16. Schorey JS, Cheng Y, Singh PP, Smith VL. Exosomes and other extracellular vesicles in host-pathogen interactions. EMBO Rep. 2015;16(1):24-43

17. Campos JH, Soares RP, Ribeiro K, Andrade AC, Batista WL, Torrecilhas AC. Extracellular vesicles: role in inflammatory responses and potential uses in vaccination in cancer and infectious diseases. J Immunol Res. 2015;2015:832057.

18. Barteneva NS, Maltsev N, Vorobjev IA. Microvesicles and intercellular communication in the context of parasitism. Front Cell Infect Microbiol. 2013;3:49.

19. Del Portillo HA, Chitnis CE. Talking to each other to initiate sexual differentiation. Cell. 2013;153(5):945-947.
20. Yáñez-Mó M, et al. Biological properties of extracellular vesicles and their physiological functions. J Extracell Vesicles. 2015;4:27066.

21. Viaud S, et al. Dendritic cell-derived exosomes for cancer immunotherapy: what's next? Cancer Res. 2010;70(4):1281-1285.

22. Viaud S, Ullrich E, Zitvogel L, Chaput N. Exosomes for the treatment of human malignancies. Horm Metab Res. 2008;40(2):82-88.

23. Ratajczak MZ, et al. Pivotal role of paracrine effects in stem cell therapies in regenerative medicine: can we translate stem cellsecreted paracrine factors and microvesicles into better therapeutic strategies? Leukemia. 2012;26(6):1166-1173.

24. Biancone L, Bruno S, Deregibus MC, Tetta C, Camussi G. Therapeutic potential of mesenchymal stem cell-derived microvesicles. Nephrol Dial Transplant. 2012;27(8):3037-3042.

25. Sun D, et al. A novel nanoparticle drug delivery system: the anti-inflammatory activity of curcumin is enhanced when encapsulated in exosomes. Mol Ther. 2010;18(9):1606-1614.

26. Alvarez-Erviti L, Seow Y, Yin H, Betts C, Lakhal S, Wood MJ. Delivery of siRNA to the mouse brain by systemic injection of targeted exosomes. Nat Biotechnol. 2012;9(4):341-345.

27. van Dommelen SM, Vader P, Lakhal S, Kooijmans SA, van Solinge WW, Wood MJ, Schiffelers RM. Microvesicles and exosomes: opportunities for cell-derived membrane vesicles in drug delivery. JControl Release. 2012;161(2):635-644.

28. Escudier B, et al. Vaccination of metastatic melanoma patients with autologous dendritic cell (DC) derived-exosomes: results of thefirst phase 
I clinical trial. J Transl Med. 2005;3(1):10.

29. Morse MA, et al. A phase I study of dexosome immunotherapy in patients with advanced nonsmall cell lung cancer. J Transl Med. 2005;3(1):9.

30. Tan A, De La Peña H, Seifalian AM. The application of exosomes as a nanoscale cancer vaccine. Int J Nanomedicine. 2010;5:889-900.

31. Nawaz M, et al. The emerging role of extracellular vesicles as biomarkers for urogenital cancers. Nat Rev Urol. 2014;11(12):688-701.

32. György B, Hung ME, Breakefield XO, Leonard JN. Therapeutic applications of extracellular vesicles: clinical promise and open questions. Annu Rev Pharmacol Toxicol. 2015;55:439-464.

33. Lener T, et al. Applying extracellular vesicles based therapeutics in clinical trials - an ISEV position paper. JExtracell Vesicles. 2015;4:30087.

34. Muralidharan-Chari V, et al. ARF6regulated shedding of tumor cell-derived plasma membrane microvesicles. Curr Biol. 2009;19(22):1875-1885.

35. Tauro BJ, et al. Comparison of ultracentrifugation, density gradient separation, and immunoaffinity capture methods for isolating human colon cancer cell line LIM1863-derived exosomes. Methods. 2012;56(2):293-304.

36. Pospichalova V, et al. Simplified protocol for flow cytometry analysis of fluorescently labeled exosomes and microvesicles using dedicated flow cytometer. J Extracell Vesicles. 2015;4:25530.

37. Xu R, Greening DW, Rai A, Ji H, Simpson RJ. Highly-purified exosomes and shed microvesicles isolated from the human colon cancer cell line LIM1863 by sequential centrifugal ultrafiltration are biochemically and functionally distinct. Methods. 2015;87:11-21.

38. Atkin-Smith GK, et al. A novel mechanism of generating extracellular vesicles during apoptosis via a beads-on-a-string membrane structure. Nat Commun. 2015;6:7439.

39. Dean WL, Lee MJ, Cummins TD, Schultz DJ, Powell DW. Proteomic and functional characterisation of platelet microparticle size classes. Thromb Haemost. 2009;102(4):711-718.

40. Heijnen HF, Schiel AE, Fijnheer R, Geuze HJ, Sixma JJ. Activated platelets release two types of membrane vesicles: microvesicles by surface shedding and exosomes derived from exocytosis of multivesicular bodies and $\alpha$-granules. Blood. 1999;94(11):3791-3799.

41. Aatonen MT, Ohman T, Nyman TA, Laitinen S, Grönholm M, Siljander PR. Isolation and characterization of platelet-derived extracellular vesicles. J Extracell Vesicles. 2014;3.

42. Pallet N, et al. A comprehensive characterization of membrane vesicles released by autophagic human endothelial cells. Proteomics. 2013;13(7):1108-1120.

43. Gould SJ, Raposo G. As we wait: coping with an imperfect nomenclature for extracellular vesicles. J Extracell Vesicles. 2013;2.

44. Witwer KW, et al. Standardization of sample collection, isolation and analysis methods in extracellular vesicle research. J Extracell Vesicles. 2013;2.

45. Lötvall J, et al. Minimal experimental requirements for definition of extracellular vesicles their functions: a position statement from the International Society for Extracellular Vesicles.
J Extracell Vesicles. 2013;26913.

46. Szajnik M, et al. Exosomes in plasma of patients with ovarian carcinoma: potential biomarkers of tumor progression and response to therapy. Gynecol Obstet (Sunnyvale). 2013;(suppl 4):3.

47. Eldh M, et al. MicroRNA in exosomes isolated directly from the liver circulation in patients with metastatic uveal melanoma. BMC Cancer. 2014;14:962.

48. Rupp AK, et al. Loss of EpCAM expression in breast cancer derived serum exosomes: role of proteolytic cleavage. Gynecol Oncol. 2011;122(2):437-446.

49. Melo SA, et al. Cancer exosomes perform cellindependent microRNA biogenesis and promote tumorigenesis. Cancer Cell. 2014;26(5):707-721.

50. Katzmann DJ, Babst M, Emr SD. Ubiquitindependent sorting into the multivesicular body pathway requires the function of a conserved endosomal protein sorting complex, ESCRT-I. Cell. 2001;106(2):145-155.

51. Hurley JH. ESCRTs are everywhere. EMBO J. 2015;34(19):2398-2407.

52. Hanson PI, Cashikar A. Multivesicular body morphogenesis. Annu Rev Cell Dev Biol. 2012;28:337-362.

53. Edgar JR, Eden ER, Futter CE. Hrs- and CD63dependent competing mechanisms make different sized endosomal intraluminal vesicles. Traffic. 2014;15(2):197-211.

54. Trajkovic K, et al. Ceramide triggers budding of exosome vesicles into multivesicular endosomes. Science. 2008;319(5867):1244-1247.

55. Ghossoub R, et al. Syntenin-ALIX exosome biogenesis and budding into multivesicular bodies are controlled by ARF6 and PLD2. Nat Commun 2014;5:3477.

56. Li B, Antonyak MA, Zhang J, Cerione RA. RhoA triggers a specific signaling pathway that generates transforming microvesicles in cancer cells. Oncogene. 2012;31(45):4740-4749.

57. Morello M, et al. Large oncosomes mediate intercellular transfer of functional microRNA. Cell Cycle. 2013;12(22):3526-3536.

58. Di Vizio D, et al. Large oncosomes in human prostate cancer tissues and in the circulation of mice with metastatic disease. Am J Pathol. 2012;181(5):1573-1584.

59. Nabhan JF, Hu R, Oh RS, Cohen SN, Lu Q. Formation and release of arrestin domaincontaining protein 1-mediated microvesicles (ARMMs) at plasma membrane by recruitment of TSG101 protein. Proc Natl Acad Sci U S A. 2012;109(11):4146-4151.

60. Moreno-Gonzalo O, Villarroya-Beltri C, SánchezMadrid F. Post-translational modifications of exosomal proteins. Front Immunol. 2014;5:383.

61. Melo-Braga MN, et al. Comprehensive quantitative comparison of the membrane proteome, phosphoproteome, and sialiome of human embryonic and neural stem cells. Mol Cell Proteomics. 2014;13(1):311-328.

62. Villarroya-Beltri C, et al. Sumoylated hnRNPA2B1 controls the sorting of miRNAs into exosomes through binding to specific motifs. Nat Commun. 2013;4:2980.

63. Bolukbasi MF, et al. miR-1289 and "Zipcode"-like sequence enrich mRNAs in microvesicles. $\mathrm{Mol}$
Ther Nucleic Acids. 2012;1:e10.

64. Koppers-Lalic D, et al. Nontemplated nucleotide additions distinguish the small RNA composition in cells from exosomes. Cell Rep. 2014;8(6):1649-1658.

65. Zaborowski MP, Balaj L, Breakefield XO, Lai CP. Extracellular vesicles: composition, biological relevance, and methods of study. BioScience. 2015;65(8):783-797.

66. Tauro BJ, Greening DW, Mathias RA, Mathivanan S, Ji H, Simpson RJ. Two distinct populations of exosomes are released from LIM1863 colon carcinoma cell-derived organoids. Mol Cell Proteomics. 2013;12(3):587-598.

67. Ji $\mathrm{H}$, et al. Deep sequencing of RNA from three different extracellular vesicle (EV) subtypes released from the human LIM1863 colon cancer cell line uncovers distinct miRNA-enrichment signatures. PLoS One. 2014;9(10):e110314.

68. Ogawa $Y$, et al. Proteomic analysis of two types of exosomes in human whole saliva. Biol Pharm Bull. 2011;34(1):13-23.

69. Théry C, Amigorena S, Raposo G, Clayton A. Isolation and characterization of exosomes from cell culture supernatants and biological fluids. Curr Protoc Cell Biol. 2006; Chapter 3:Unit 3.22.

70. Greening DW, Xu R, Ji H, Tauro BJ, Simpson RJ. A protocol for exosome isolation and characterization: evaluation of ultracentrifugation, densitygradient separation, and immunoaffinity capture methods. Methods Mol Biol. 2015;1295:179-209.

71. Lobb RJ, et al. Optimized exosome isolation protocol for cell culture supernatant and human plasma. J Extracell Vesicles. 2015;4:27031.

72. Webber J, Clayton A. How pure are your vesicles? JExtracell Vesicles. 2013;2.

73. Alvarez ML, Khosroheidari M, Kanchi Ravi R, DiStefano JK. Comparison of protein, microRNA, and mRNA yields using different methods of urinary exosome isolation for the discovery of kidney disease biomarkers. Kidney Int . 2012;82(9):1024-1032.

74. Ji H, et al. Proteome profiling of exosomes derived from human primary and metastatic colorectal cancer cells reveal differential expression of key metastatic factors and signal transduction components. Proteomics. 2013;13(10-11):1672-1686.

75. Handlogten MW, Stefanick JF, Deak PE, Bilgicer B. Affinity-based precipitation via a bivalent peptidic hapten for the purification of monoclonal antibodies. Analyst. 2014;139(17):4247-4255.

76. Atai NA, et al. Heparin blocks transfer of extracellular vesicles between donor and recipient cells. J Neurooncol. 2013;115(3):343-351.

77. Balaj $\mathrm{L}$, et al. Heparin affinity purification of extracellular vesicles. Sci Rep. 2015;5:10266.

78. Raboudi N, Julian J, Rohde LH, Carson DD. Identification of cell-surface heparin/heparan sulfatebinding proteins of a human uterine epithelial cell line (RL95). J Biol Chem. 1992;267(17):11930-11939.

79. Menck K, et al. Tumor-derived microvesicles mediate human breast cancer invasion through differentially glycosylated EMMPRIN. J Mol Cell Biol. 2015;7(2):143-153.

80. Erdbrügger U, Lannigan J. Analytical challenges of extracellular vesicle detection: a comparison of different techniques [published online ahead of print December 9, 2015]. Cytometry A. 
doi:10.1002/cyto.a.22795.

81. Smith ZJ, et al. Single exosome study reveals subpopulations distributed among cell lines with variability related to membrane content. J Extracell Vesicles. 2015;4:28533.

82. Gagni P, et al. Combined mass quantitation and phenotyping of intact extracellular vesicles by a microarray platform. Anal Chim Acta. 2016;902:160-167.

83. Tosar JP, Gámbaro F, Sanguinetti J, Bonilla B, Witwer KW, Cayota A. Assessment of small RNA sorting into different extracellular fractions revealed by high-throughput sequencing of breast cell lines. Nucleic Acids Res. 2015;43(11):5601-5616.

84. Peinado $\mathrm{H}$, et al. Melanoma exosomes educate bone marrow progenitor cells toward a prometastatic phenotype through MET. Nat Med. 2012;18(6):883-891.

85. Galindo-Hernandez O, et al. Elevated concentration of microvesicles isolated from peripheral blood in breast cancer patients. Arch Med Res. 2013;44(3):208-214.

86. Melo SA, et al. Glypican-1 identifies cancer exosomes and detects early pancreatic cancer. Nature. 2015;523(7559):177-182.

87. Costa-Silva B, et al. Pancreatic cancer exosomes initiate pre-metastatic niche formation in the liver. Nat Cell Biol. 2015;17(6):816-826.

88. Sáenz-Cuesta M, et al. Methods for extracellular vesicles isolation in a hospital setting. Front Immunol. 2015;6:50.

89. Jayachandran M, Miller VM, Heit JA, Owen WG. Methodology for isolation, identification and characterization of microvesicles in peripheral blood. JImmunol Methods. 2012;375(1-2):207-214.

90. Muller L, Hong CS, Stolz DB, Watkins SC, Whiteside TL. Isolation of biologically-active exosomes from human plasma. J Immunol Methods. 2014;411:55-65.

91. van der Meel R, Krawczyk-Durka M, van Solinge WW, Schiffelers RM. Toward routine detection of extracellular vesicles in clinical samples. Int $J$ Lab Hematol. 2014;36(3):244-253.

92. Lacroix R, et al. Standardization of pre-analytical variables in plasma microparticle determination: results of the International Society on Thrombosis and Haemostasis SSC Collaborative workshop [published online ahead of print April 2, 2013]. J Thromb Haemost. doi:10.1111/jth.12207.

93. International Society for Advancement of Cytometry. ISAC Web site. http://isac-net.org. Accessed February 17, 2016.

94. Böing AN, van der Pol E, Grootemaat AE, Coumans FA, Sturk A, Nieuwland R. Single-step isolation of extracellular vesicles by size-exclusion chromatography. J Extracell Vesicles. 2014;3:23430.

95. Welton JL, Webber JP, Botos LA, Jones M, Clayton A. Ready-made chromatography columns for extracellular vesicle isolation from plasma. J Extracell Vesicles. 2015;4:27269.

96. Jakobsen KR, Paulsen BS, Bæk R, Varming K, Sorensen BS, Jørgensen MM. Exosomal proteins as potential diagnostic markers in advanced non-small cell lung carcinoma. J Extracell Vesicles. 2015;4:26659.

97. Shao H, et al. Chip-based analysis of exosomal mRNA mediating drug resistance in glioblas- toma. Nat Commun. 2015;6:6999.

98. Shao H, et al. Protein typing of circulating microvesicles allows real-time monitoring of glioblastoma therapy. Nat Med. 2012;18(12):1835-1840.

99. Kanwar SS, Dunlay CJ, Simeone DM, Nagrath S. Microfluidic device (ExoChip) for on-chip isolation, quantification and characterization of circulating exosomes. Lab Chip. 2014;14(11):1891-1900.

100.Im H, et al. Label-free detection and molecular profiling of exosomes with a nano-plasmonic sensor. Nat Biotechnol. 2014;32(5):490-495.

101. Madhavan B, et al. Combined evaluation of a panel of protein and miRNA serum-exosome biomarkers for pancreatic cancer diagnosis increases sensitivity and specificity. Int J Cancer. 2015;136(11):2616-2627.

102. Mathivanan S, Lim JW, Tauro BJ, Ji H, Moritz RL, Simpson RJ. Proteomics analysis of A33 immunoaffinity-purified exosomes released from the human colon tumor cell line LIM1215 reveals a tissue-specific protein signature. Mol Cell Proteomics. 2010;9(2):197-208.

103. Ji H, et al. Difference gel electrophoresis analysis of Ras-transformed fibroblast cell-derived exosomes. Electrophoresis. 2008;29(12):2660-2671.

104.Peptide Atlas. ISB Web site. http://www.peptideatlas.org/PASS/PASSO0749. Accessed February 17, 2016.

105. Charrin S, le Naour F, Silvie O, Milhiet PE, Boucheix C, Rubinstein E. Lateral organization of membrane proteins: tetraspanins spin their web. Biochem J. 2009;420(2):133-154.

106.Janas T, Janas MM, Sapoń K, Janas T. Mechanisms of RNA loading into exosomes. FEBS Lett. 2015;589(13):1391-1398.

107. Arraud N, et al. Extracellular vesicles from blood plasma: determination of their morphology, size, phenotype and concentration.J Thromb Haemost. 2014;12(5):614-627.

108. Prescher J, et al. Super-resolution imaging of ESCRT-proteins at HIV-1 assembly sites. PLOS Pathog. 2015;11(2):e1004677.

109. Müller B, Heilemann M. Shedding new light on viruses: super-resolution microscopy for studying human immunodeficiency virus. Trends Microbiol. 2013;21(10):522-533.

110.Parolini I, et al. Microenvironmental $\mathrm{pH}$ is a key factor for exosome traffic in tumor cells. J Biol Chem. 2009;284(49):34211-34222.

111. Montecalvo A, et al. Mechanism of transfer of functional microRNAs between mouse dendritic cells via exosomes. Blood. 2012;119(3):756-766.

112. Escrevente C, Keller S, Altevogt P, Costa J. Interaction and uptake of exosomes by ovarian cancer cells. BMC Cancer. 2011;11:108.

113. Svensson KJ, et al. Exosome uptake depends on ERK1/2-heat shock protein 27 signaling and lipid Raft-mediated endocytosis negatively regulated by caveolin-1. J Biol Chem. 2013;288(24):17713-17724.

114. Morelli AE, et al. Endocytosis, intracellular sorting, and processing of exosomes by dendritic cells. Blood. 2004;104(10):3257-3266.

115. Nanbo A, Kawanishi E, Yoshida R, Yoshiyama $\mathrm{H}$. Exosomes derived from EpsteinBarr virus-infected cells are internalized via caveola-dependent endocytosis and promote phenotypic modulation in target cells. JVirol.
2013;87(18):10334-10347.

116. Fitzner D, et al. Selective transfer of exosomes from oligodendrocytes to microglia by macropinocytosis. J Cell Sci. 2011;124(pt 3):447-458.

117. Feng D, et al. Cellular internalization of exosomes occurs through phagocytosis. Traffic. 2010;11(5):675-687.

118. Greening DW, Gopal SK, Xu R, Simpson RJ, Chen W. Exosomes and their roles in immune regulation and cancer. Semin Cell Dev Biol. 2015;40:72-81.

119. Théry C, Ostrowski M, Segura E. Membrane vesicles as conveyors of immune responses. Nat Rev Immunol. 2009;9(8):581-593.

120. Robbins PD, Morelli AE. Regulation of immune responses by extracellular vesicles. Nat Rev Immunol. 2014;14(3):195-208.

121. Lai RC, et al. Exosome secreted by MSC reduces myocardial ischemia/reperfusion injury. Stem Cell Res. 2010;4(3):214-222.

122. Ghosh A, et al. Rapid isolation of extracellular vesicles from cell culture and biological fluids using a synthetic peptide with specific affinity for heat shock proteins. PLoS One. 2014;9(10):e110443.

123. Christianson HC, Svensson KJ, van Kuppevelt TH, Li JP, Belting M. Cancer cell exosomes depend on cell-surface heparan sulfate proteoglycans for their internalization and functional activity. Proc Natl Acad Sci U SA. 2013;110(43):17380-17385.

124. Yoo CE, et al. A direct extraction method for microRNAs from exosomes captured by immunoaffinity beads. Anal Biochem. 2012;431(2):96-98.

125. Clayton A, et al. Analysis of antigen presenting cell derived exosomes, based on immuno-magnetic isolation and flow cytometry. JImmunol Methods. 2001;247(1-2):163-174.

126. Keryer-Bibens C, et al. Exosomes released by EBV-infected nasopharyngeal carcinoma cells convey the viral latent membrane protein 1 and the immunomodulatory protein galectin $9 . B M C$ Cancer. 2006;6:283.

127. Coren LV, Shatzer T, Ott DE. CD45 immunoaffinity depletion of vesicles from Jurkat $\mathrm{T}$ cells demonstrates that exosomes contain CD45: no evidence for a distinct exosome/HIV-1 budding pathway. Retrovirology. 2008;5:64.

128. Mercier SK, et al. The microvesicle component of HIV-1 inocula modulates dendritic cell infection and maturation and enhances adhesion to and activation of T lymphocytes. PLoS Pathog. 2013;9(10):e1003700.

129. Caby MP, Lankar D, Vincendeau-Scherrer C, Raposo G, Bonnerot C. Exosomal-like vesicles are present in human blood plasma. Int Immunol. 2005;17(7):879-887.

130. Oksvold MP, et al. Expression of B-cell surface antigens in subpopulations of exosomes released from B-cell lymphoma cells. Clin Ther. 2014;36(6):847-862.

131. Wiley RD, Gummuluru S. Immature dendritic cell-derived exosomes can mediate HIV-1 trans infection. Proc Natl Acad Sci U S A . 2006;103(3):738-743.

132. Koga K, et al. Purification, characterization and biological significance of tumor-derived exosomes. Anticancer Res. 2005;25(6A):3703-3707.

133. Wang Z, et al. Ciliated micropillars for the micro- 
fluidic-based isolation of nanoscale lipid vesicles. Lab Chip. 2013;13(15):2879-2882.

134.Liga A, Vliegenthart AD, Oosthuyzen W, Dear JW, Kersaudy-Kerhoas M. Exosome isolation: a microfluidic road-map. Lab Chip. 2015;15(11):2388-2394.

135. Lee C, et al. Exosomes mediate the cytoprotective action of mesenchymal stromal cells on hypoxia-induced pulmonary hypertension. Circulation. 2012;126(22):2601-2611.

136. Kordelas L, et al. MSC-derived exosomes: a novel tool to treat therapy-refractory graft-versus-host disease. Leukemia. 2014;28(4):970-973.

137. Van Deun J, et al. The impact of disparate isolation methods for extracellular vesicles on downstream RNA profiling. J Extracell Vesicles. 2014;3:24858.

138. Cheruvanky A, et al. Rapid isolation of urinary exosomal biomarkers using a nanomembrane ultrafiltration concentrator. Am J Physiol Renal Physiol. 2007;292(5):F1657-F1661.

139. Merchant ML, et al. Microfiltration isolation of human urinary exosomes for characterization by
MS. Proteomics Clin Appl. 2010;4(1):84-96. 140. Grant R, et al. A filtration-based protocol to isolate human plasma membrane-derived vesicles and exosomes from blood plasma. J Immunol Methods. 2011;371(1-2):143-151.

141. Filipe V, Hawe A, Jiskoot W. Critical evaluation of Nanoparticle Tracking Analysis (NTA) by NanoSight for the measurement of nanoparticles and protein aggregates. Pharm Res. 2010;27(5):796-810.

142. Maas SL, et al. Possibilities and limitations of current technologies for quantification of biological extracellular vesicles and synthetic mimics. J Control Release. 2015;200:87-96.

143. van der Pol E, et al. Particle size distribution of exosomes and microvesicles determined by transmission electron microscopy, flow cytometry, nanoparticle tracking analysis, and resistive pulse sensing. J Thromb Haemost. 2014;12(7):1182-1192.

144.Dragovic RA, Southcombe JH, Tannetta DS, Redman CW, Sargent IL. Multicolor flow cytometry and nanoparticle tracking analysis of extracellular vesicles in the plasma of normal pregnant and pre-eclamptic women. Biol Reprod. 2013;89(6):151.

145. Dragovic RA, et al. Isolation of syncytiotrophoblast microvesicles and exosomes and their characterisation by multicolour flow cytometry and fluorescence Nanoparticle Tracking Analysis. Methods. 2015;87:64-74.

146. Sokolova V, et al. Characterisation of exosomes derived from human cells by nanoparticle tracking analysis and scanning electron microscopy. Colloids Surf B Biointerfaces. 2011;87(1):146-150.

147. Headland SE, Jones HR, D'Sa AS, Perretti M, Norling LV. Cutting-edge analysis of extracellular microparticles using ImageStream $(\mathrm{X})$ imaging flow cytometry. Sci Rep. 2014;4:5237.

148. Yoshioka Y, et al. Ultra-sensitive liquid biopsy of circulating extracellular vesicles using ExoScreen. Nat Commun. 2014;5:3591.

149. Shao H, et al. Magnetic nanoparticles and microNMR for diagnostic applications. Theranostics. 2012;2(1):55-65. 